\title{
Real-time Implementation of Sensor Read and Record using Android Application-2
}

\author{
Vishesh $\mathbf{S}^{1}$, Satish $\mathrm{K}^{2}$, Narendra Vadavadagi ${ }^{2}$, Tammannagouda ${ }^{2}$, Chethan $\mathrm{C}^{2}$, Lohith $\mathrm{S}^{2}$ \\ B.E, Department of Telecommunication Engineering, BNM Institute of Technology, Bangalore, India ${ }^{1}$ \\ Student, Department of Electronics and Communication Engineering, BMSCE, Bangalore, India ${ }^{2}$
}

\begin{abstract}
A System can be defined as an arrangement in which all units assemble and work together according to a program or plan. An embedded system is a system that has software embedded into computer-hardware, which makes a system dedicated for an application or specific part of an application or product or part of a larger system. Today Embedded systems are used in real-time computing applications like temperature sensing, environmental gas sensing, medical applications, automotive, military applications etc...Embedded systems may or may not have user interface. In systems dedicated only to one task, there is no user interface provided. In this paper we have developed an embedded system with an android interface. The android application developed by us is capable of wirelessly monitoring real-time sensor values. In the previous paper titled "Practical Implementation of Real-time Sensing of Sensor values using Android Applicaion-1" we had tested our Third party developed Android application with numerous sensors-LPG sensors, Alcohol sensing, Range detection using ultrasonic sensors and Temperature-Humidity sensing. In this paper we are applying the embedded system design to many other sensors like $\mathrm{CO}, \mathrm{CO}_{2}$ and $\mathrm{SO}_{2}$ sensors; IR sensors and Pressure sensors.
\end{abstract}

Keywords: real-time computing applications, user interface, Third party developed Android application, $\mathrm{CO}, \mathrm{CO}_{2}$ and $\mathrm{SO}_{2}$ sensors, IR sensors and Pressure sensors.

\section{INTRODUCTION}

An Embedded system can be perceived as single equipment or an aggregate of multiple equipment. But we would like to consider/define it as single equipment. At the core of each embedded system are one or more functionalities that each system is expected to provide. Each of these functionalities provided by the system is referred to as "functional block" and the embedded software used to make each system function is broken down hierarchically into "functional unit" and "program unit".

Figure 1 shows the structure of embedded system. Following are the constituents of an embedded system structure.

- Functional Block- Normally, an embedded system provides multiple functionalities. A combination of a specific hardware and specific embedded software, which forms one functional block, is necessary to realize each of these functionalities.

- Embedded Software- It is an entity that constitutes a part of the embedded system, and is composed of a specific combination of functional units.

- Functional unit- It is an entity that constitutes a part of the embedded software, and is composed of a specific combination of program units.

- Program unit-It is an entity of the lowest level (e.g. compile or test unit) that constitutes a part of the functional unit.

\section{EMBEDDED SYSTEM LIFE CYCLE}

In the development of a software application on a standard platform, SDLC model is preferred and it involves multiple stages of analysis, development and integration. Unlike the design of a software application, embedded system design involves design of hardware and software in parallel.

This parallel approach will reduce time and cost, complexity and desired product and service output. Figure 2 shows the Embedded System life cycle and its different phases.

Following are the phases of Embedded System life cycle

- Phase 1 - Product specification

- Phase 2 - Hardware / Software partition

- Phase 3 - Iteration and Implementation 
- Phase 4 - Detailed Hardware / Software design

- Phase 5 - Hardware / Software integration

- Phase 6 - Testing

- Phase 6-7 - Product release and Marketing

- Phase 7 - Maintenance and Upgrade.

Also, a considerable amount of iteration and optimization occurs within phases and between phases. There are various models of embedded system development life cycle.

Few are listed below

- Classical Embedded Product Development Life cycle model.

- Waterfall model / Linear EDLC model

- V-model

- Spiral model

- Prototyping / Evolutionary model.

We follow the Prototyping / Evolutionary model. It is similar to the iterative model and the product is developed in multiple cycles. The only difference is that this model produces the more refined prototype of the product at the end of each cycle instead of functionality / feature addition in each cycle as perform by the iterative model. There won't be any commercial deployment of the prototype of the product at each cycle's end. The shortcomings of the proto-model after each cycle are evaluated and are fixed in the next cycle. Figure 3 shows the Prototyping / Evolutionary model of embedded system design.

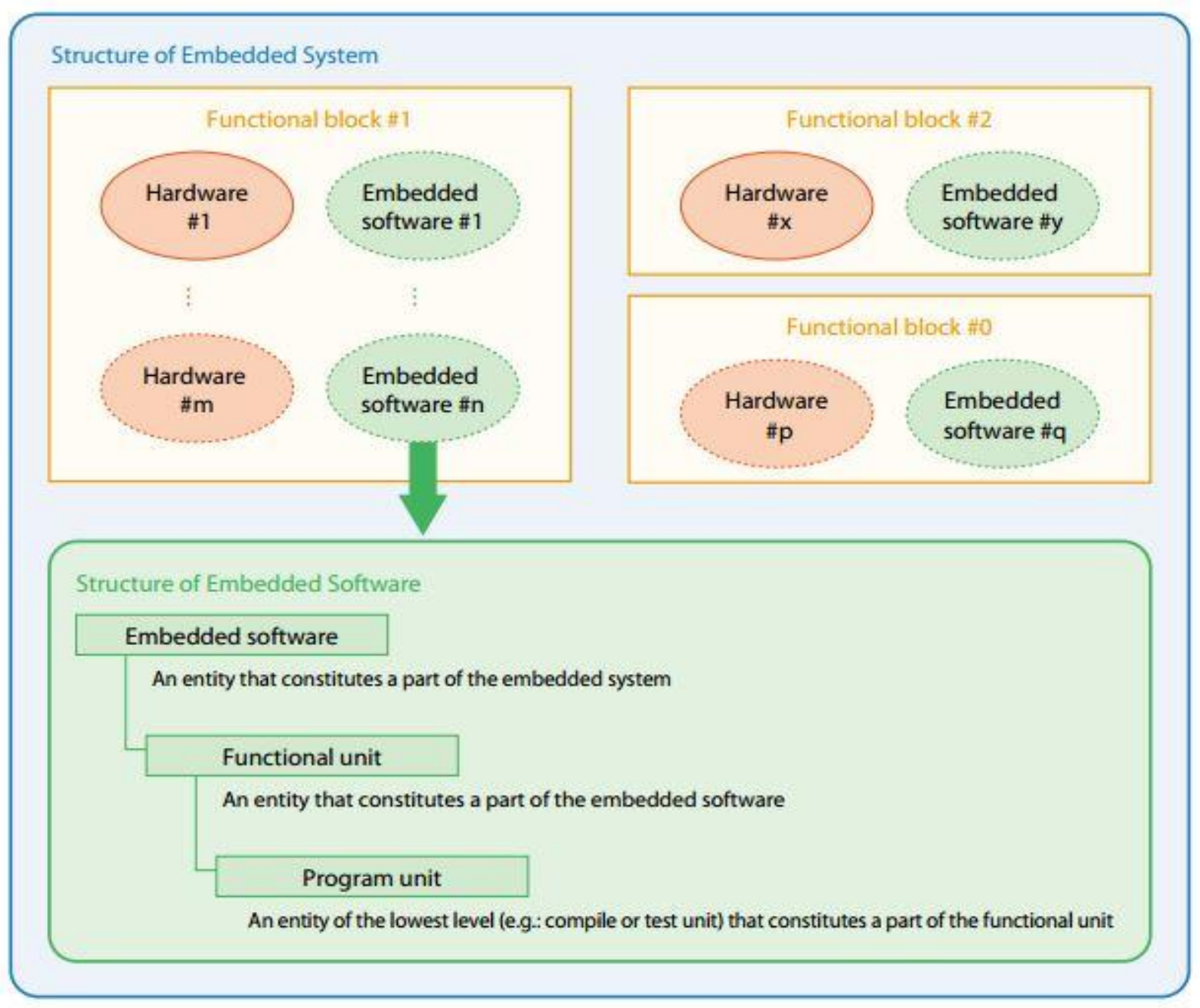

Figure 1 shows the structure of embedded system 
International Journal of Advanced Research in Computer and Communication Engineering ISO 3297:2007 Certified

Vol. 6, Issue 5, May 2017

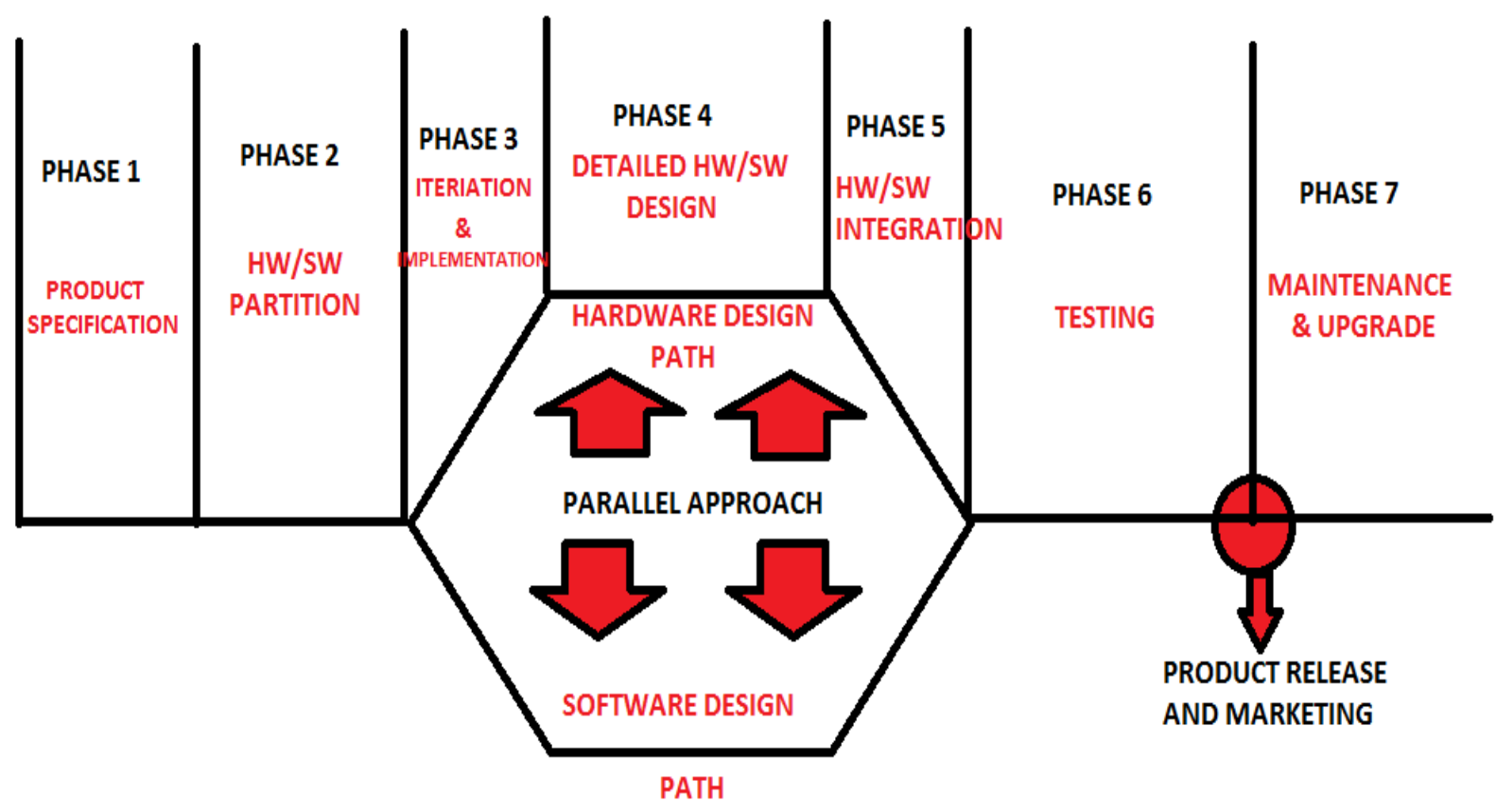

Figure 2 shows the Embedded System life cycle and its different phases

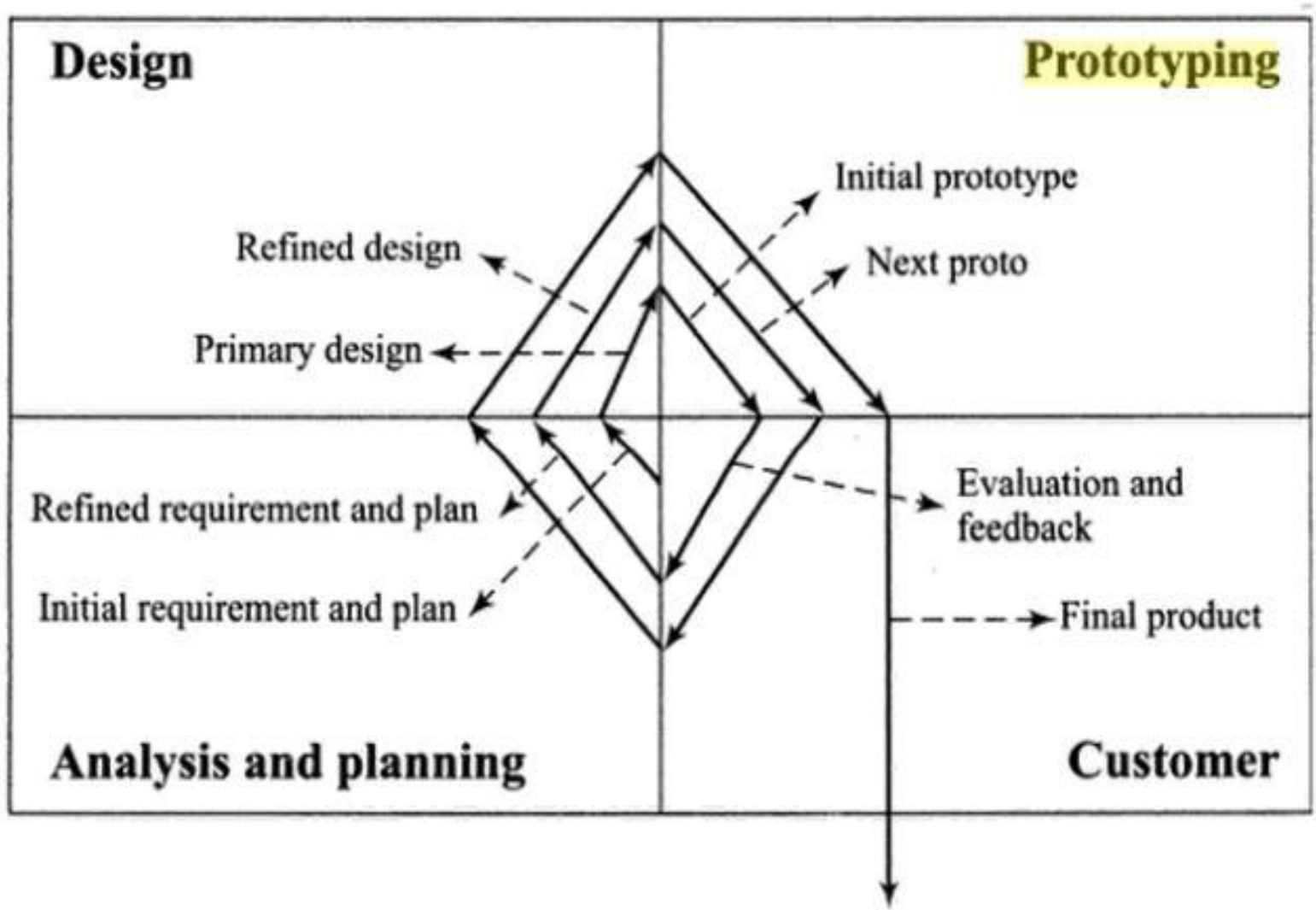

Figure 3 shows the Prototyping / Evolutionary model of embedded system design 
International Journal of Advanced Research in Computer and Communication Engineering ISO 3297:2007 Certified

Vol. 6, Issue 5, May 2017

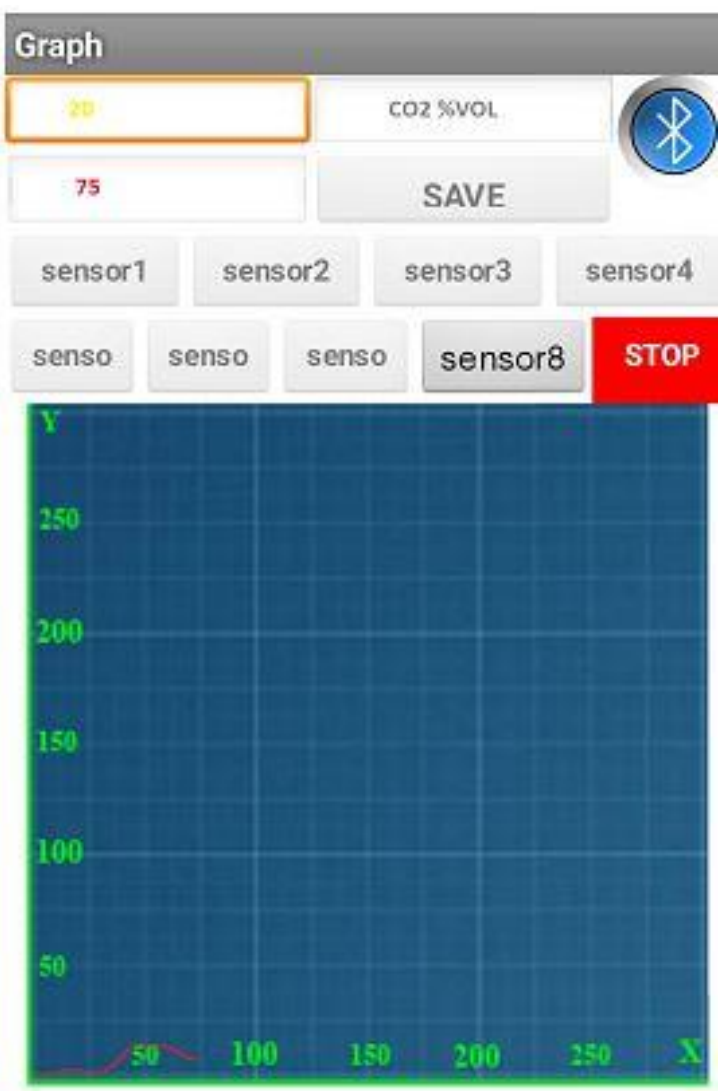

Figure 4 shows the monitoring of $\mathrm{CO}_{2}$ emitted by a vehicle in $\%$ vol using MQ135

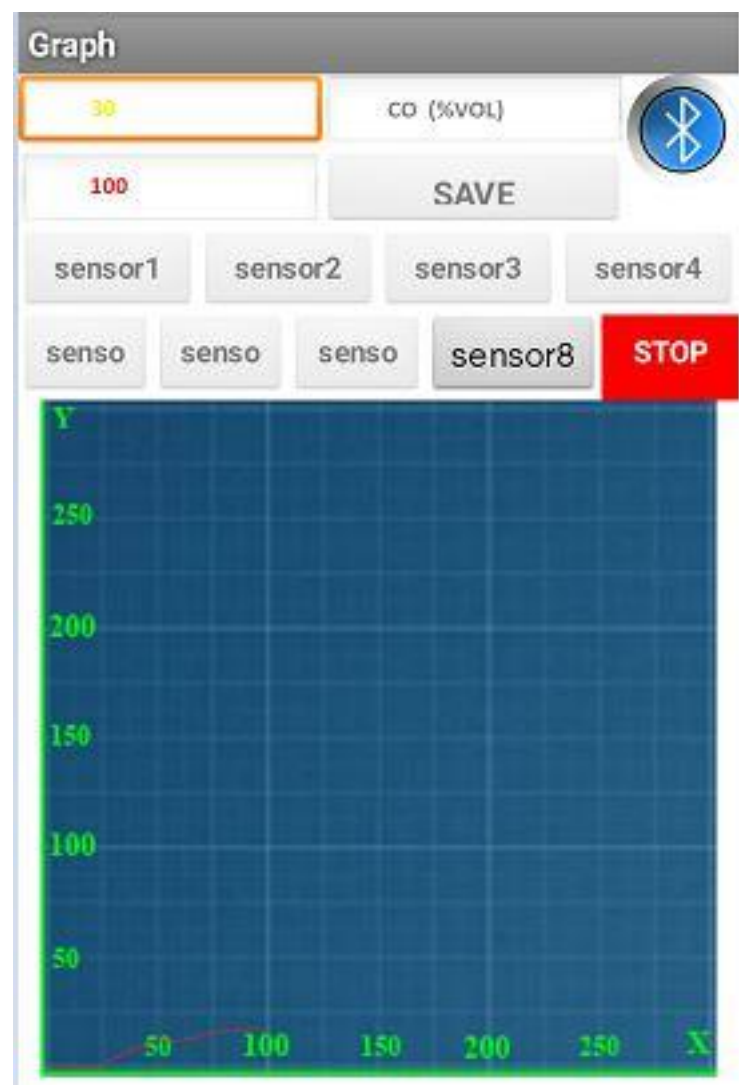

Figure 5 shows the monitoring of $\mathrm{CO}$ in \% vol using MQ7 
International Journal of Advanced Research in Computer and Communication Engineering ISO 3297:2007 Certified

Vol. 6, Issue 5, May 2017

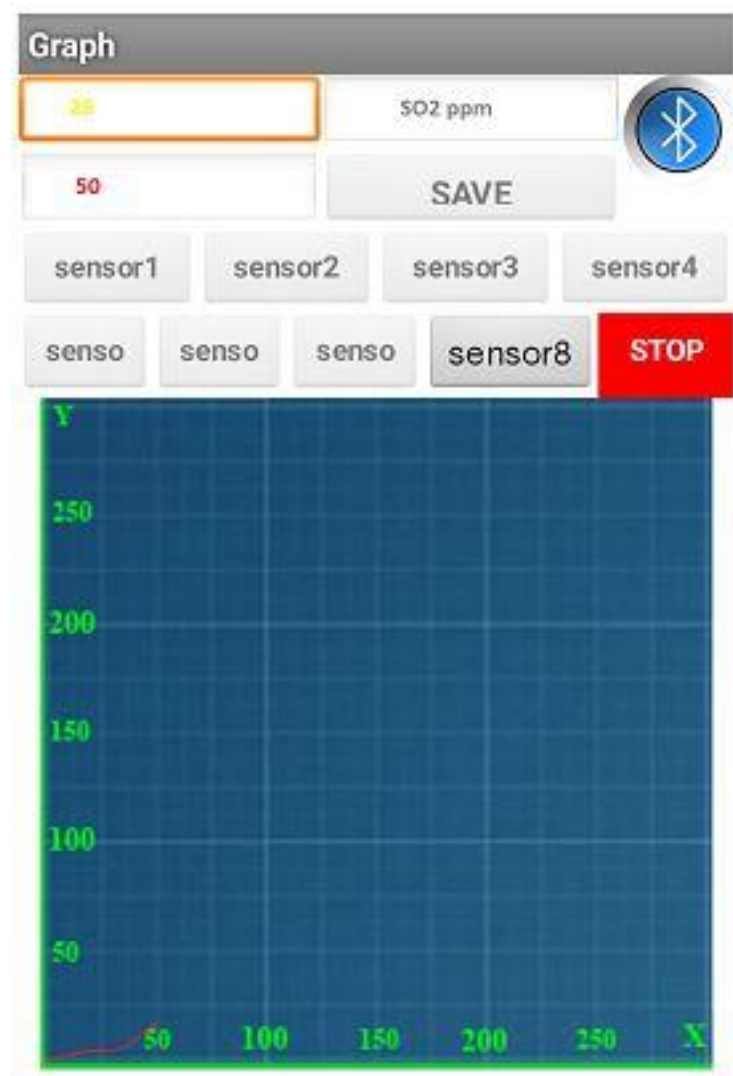

Figure 6 shows the monitoring of $\mathrm{SO}_{2}$ in ppm using MQ136

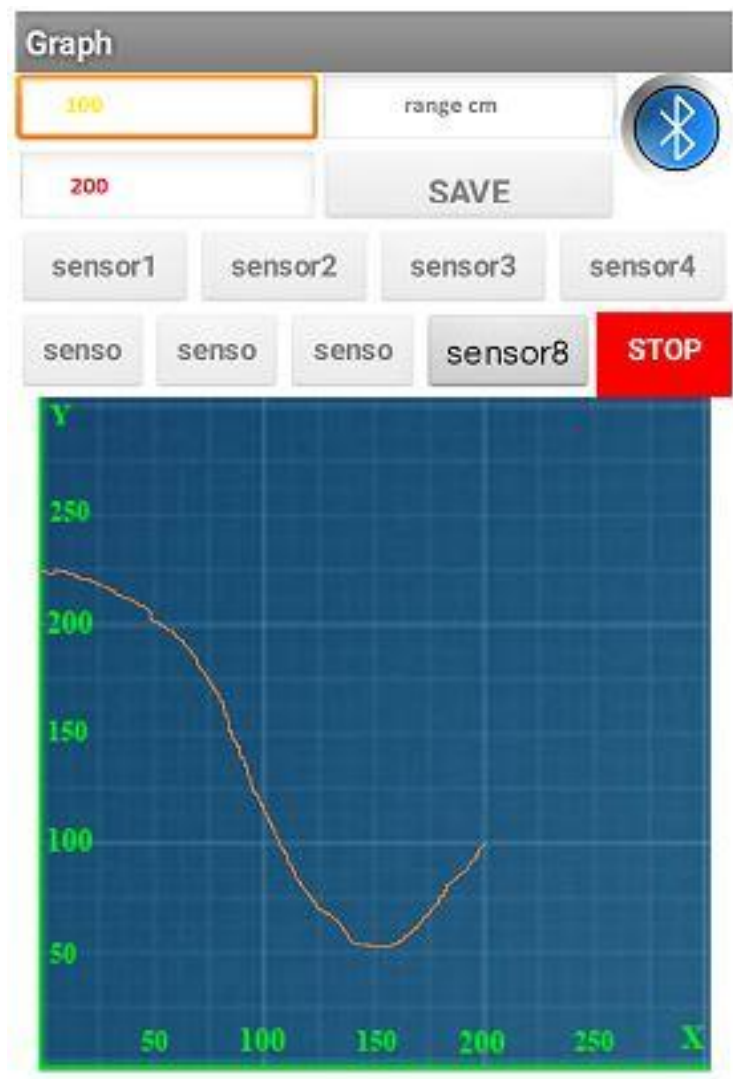

Figure 7 shows range detection using IR sensors 


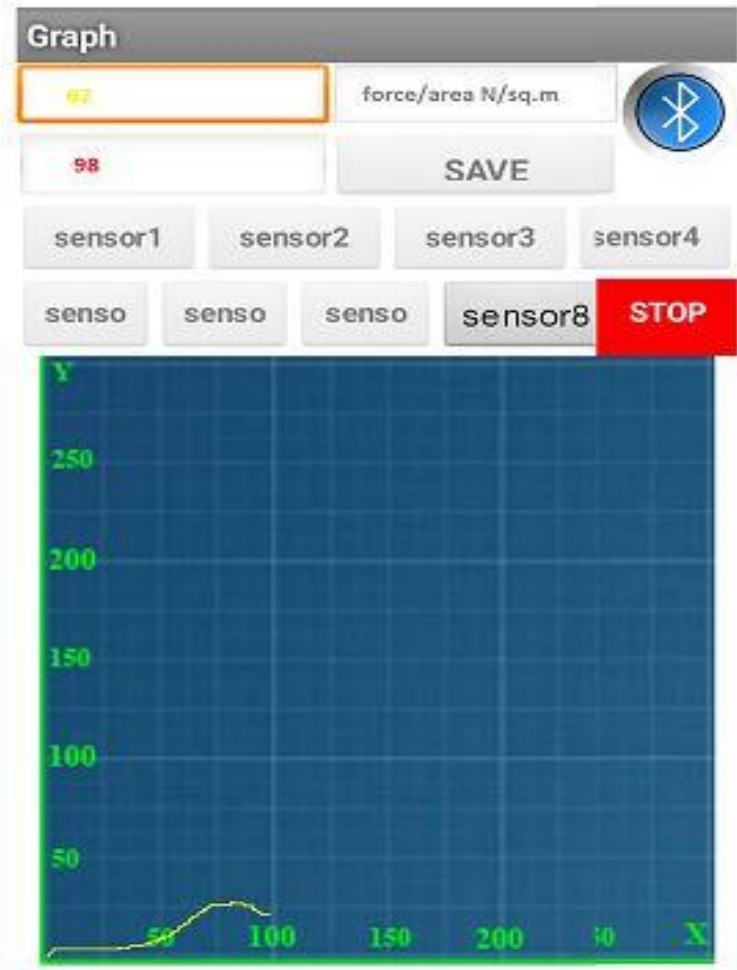

Figure 8 shows the readings of Force/area v/s time using android application

\section{III.DETECTION OF CO, $\mathrm{CO}_{2} \mathrm{AND} \mathrm{SO}_{2}$}

Greenhouse gases are the gases which trap heat in the atmosphere. Carbon dioxide $\left(\mathrm{CO}_{2}\right)$, Methane $\left(\mathrm{CH}_{4}\right)$, Nitrous oxide and fluorinated gases are the major greenhouse gases. Carbon dioxide $\left(\mathrm{CO}_{2}\right)$ is the primary greenhouse gas emitted through human activities like combustion of fossil fuels, industrial emission and in the process of generating electricity. Excess of $\mathrm{CO}_{2}$ in the atmosphere leads to increase in the global temperature further leading to melting of glaciers at the poles, called global warming and leads to increase in the water levels. This causes submerging of low lying lands under water. Detection of $\mathrm{CO}_{2}$ is vital to monitor the levels of $\mathrm{CO}_{2}$ in a particular region and period of time. Figure 4 shows the monitoring of $\mathrm{CO}_{2}$ emitted by a vehicle in \% vol using MQ135. [1] Burning of fossil fuels, industrial emission and vehicular emission contains yet another dangerous gas called carbon monoxide (CO). $\mathrm{CO}$ is found in fuels produced any time during burning of fuel in cars or trucks, in industries, furnaces, smoking etc.... Continuous inhalation of $\mathrm{CO}$ leads to $\mathrm{CO}$ poisoning. Most common symptoms of $\mathrm{CO}$ poisoning are headache, dizziness, weakness, stomach upset, vomiting, chest pain and confusion. $\mathrm{CO}$ in excess can even be fatal. Figure 5 shows the monitoring of $\mathrm{CO}$ using android application and $\mathrm{MQ7}$ sensor. [2] Sulphur dioxide $\left(\mathrm{SO}_{2}\right)$ is another deadly gas emitted mainly due to burning of fossil fuels by power plants, in vehicles and other industrial facilities. Exposure to $\mathrm{SO}_{2}$ can harm the human respiratory system by causing Asthma and other respiratory problems. Figure 6 shows the monitoring levels of $\mathrm{SO}_{2}$ using smartphone application and MQ136 sensor. [3]

\section{IV.ANDROID APPLICATION TO MONITOR OTHER PARAMETERS}

Few other parameters have been targeted in this paper and the upcoming research papers.

- Range detection using IR sensors- The distance between the source and the target can be easily measured by using an IR sensor. The IR sensor consists of a Tx bulb, which emits electromagnetic radiation (EMR) [4] of wavelength greater/longer than that of visible light [5]. The emitted radiation travels until it is being interrupted by any object in its path. In this case the Transmitted radiation is reflected by the target/interrupting object and is received by the Rx bulb of the IR sensor [6]. Range is calculated. Figure 7 shows the range measurement and display using android application

- Pressure sensing (or force sensing per given area) - Force can be measured at a particular area using force sensors. WKT, $\mathrm{P}=\mathrm{F} / \mathrm{A}$

Where, $\mathrm{P}=$ Pressure $(\mathrm{Pa})$

$\mathrm{F}=$ Force $(\mathrm{N})$

$\mathrm{A}=$ Area (sq.m) 
So measuring force on a particular area can give you the pressure in Pa (pascal) at that area [7]. Figure 8 shows the readings of Force/area v/s time using android application.

\section{CONCLUSIONS}

As promised, the android application developed by us can read and record the real-time values from almost any sensor. In this paper we have sincerely put in our efforts to measure concentrations of $\mathrm{CO}, \mathrm{CO}_{2}$ and $\mathrm{SO}_{2}$ from sources or in the atmosphere at a particular region. Also range detection using IR sensors and Force/area measurement was done and displayed using a third party application by name "sense_graph" installed in the android smartphone.

\section{REFERENCES}

[1] MQ135 Datasheet- https://www.olimex.com/Products/Components/Sensors/...MQ135/...SNS-MQ135.pdf

[2] MQ7 Datasheet- https://www.sparkfun.com/datasheets/Sensors/Biometric/MQ-7.pdf

[3] MQ136 Datasheet- www.sensorica.ru/pdf/MQ-136.pdf [4] Microsoft OS- https://www.microsoft.com/en-in/windows/

[4] Electromagnetic Spectrum - Introduction - Imagine the Universe! - NASA- https://imagine.gsfc.nasa.gov/science/toolbox/emspectrum1.html

[5] Visible Light Waves - Science@NASA- https://science.hq.nasa.gov/kids/imagers/ems/visible.html

[6] IR sensor datasheet- https://cdn-learn.adafruit.com/downloads/pdf/ir-sensor.pdf

[7] www.sengpielaudio.com/calculator-pressureunits.htm

[8] "Android Application to Read and Record Data from Multiple Sensors” IJARCCE- DOI: 10.17148/IJARCCE.2017.6587

\section{BIOGRAPHIES}

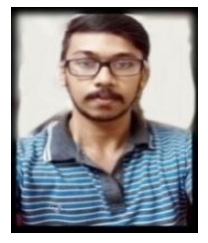

VISHESH S born on $13^{\text {th }}$ June 1992, hails from Bangalore (Karnataka) and has completed B.E in Telecommunication Engineering from VTU, Belgaum, Karnataka in 2015. He also worked as an intern under Dr Shivananju BN, Department of Instrumentation, IISc, Bangalore. His research interests include Embedded Systems, Wireless Communication and Medical Electronics. He is also the Founder and Managing Director of the company Konigtronics Private Limited. He has guided over a hundred students/lecturers/interns/professionals in their research works and projects. He is also the co-author of many International Research Papers. He is currently pursuing MBA. Presently Konigtronics Private Limited has extended its services in the field of Real Estate, Webpage Designing and Entrepreneurship.

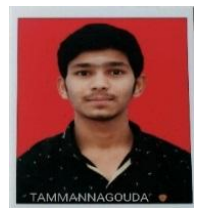

TAMMANNAGOUDA hails from Gulbarga, Karnataka. He is currently pursuing BE in Electronics and Communication Engineering at BMSCE, Bengaluru. His areas of interest include Networking and embedded systems.

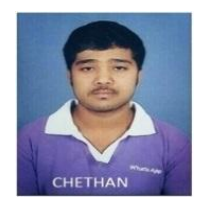

CHETHAN C hails from Bangalore, Karnataka. He is currently pursuing BE in Electronics and Communication Engineering at BMSCE, Bengaluru. His areas of interest include VHDL and embedded systems.

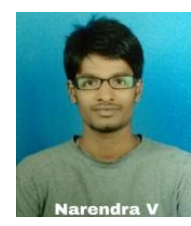

NARENDRA VADAVADAGI hails from Gadag, Karnataka. He is currently pursuing BE in Electronics and Communication Engineering at BMSCE, Bengaluru. His areas of interest include Networking and embedded systems.

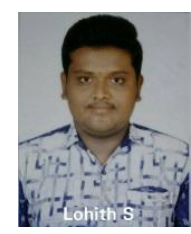

LOHITH $\mathbf{S}$ hails from Bangalore, Karnataka. He is currently pursuing BE in Electronics and Communication Engineering at BMSCE, Bengaluru. His areas of interest include VHDL and embedded systems.

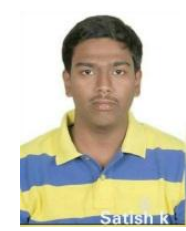

SATISH K hails from Bangalore, Karnataka. He is currently pursuing BE in Electronics and Communication Engineering at BMSCE, Bengaluru. His areas of interest include Verilog and embedded systems. 